Funding: This work was supported through grants from the UK Medical Research Council (grant No 9322050), the Swedish Council for Social Research (grant No 94/0157), and the Swedish Medical Research Council (grant No 5446). During part of her work on this study IK was in receipt of a Royal Society postdoctoral research fellowship.

Conflict of interest: None

1 Barker DJP, Winter PD, Osmond C, Margetts B. Weight in infancy and death from ischaemic heart disease Lancet 1989;ii:577-80.

2 Osmond C, Barker DJP, Winter PD, Fall CHD, Simmonds SJ. Early growth and death from cardiovascular disease in women. BMJ 1993;307: $1519-24$

3 Barker DJP, Osmond C, Simmonds SJ, Wield GA. The relation of small head circumference and thinness at birth to death from cardiovascular disease. $B M J$ 1993;306:422-6.

4 Stein CE, Fall CHD, Kumaran K, Osmond C, Cox V, Barker DJP. Fetal growth and coronary heart disease in South India. Lancet 1996;348 $1269-73$

5 Frankel S, Elwood P, Sweetnam P, Yarnell J, Davey Smith G. Birth weight, body mass index in middle age, and incident coronary heart disease. Lancet 1996;348:1478-80.

6 Rich-Edwards JW, Stampfer MJ, Manson JE, Rosner B, Hankinson SE, Colditz GA, et al. Birth weight and risk of cardiovascular disease in a cohort of women followed up since 1976. BMJ 1997:315:396-400.

7 Forsén TJ, Eriksson JG, Tuomilehto J, Teramo K, Osmond C, Barker DJP. Mother's weight in pregnancy and coronary heart disease in a cohort of Finnish men: follow up study. BMJ 1997;315:837-40.

8 Leon DA, Ben-Shlomo Y. Pre-adult influences on cardiovascular disease and cancer. In: Kuh D, Ben-Shlomo Y, eds. Life course influences on adult disease. Oxford: Oxford University Press, 1997.

9 Eriksson M, Tibblin G, Cnattingius S. Low birth weight and ischaemic heart disease. Lancet 1994;343:731.

10 Paneth N, Susser M. Early origin of coronary heart disease (the "Barker hypothesis"). BMJ 1995;310:411-2.
11 Joseph KS, Kramer MS. Review of the evidence of fetal and early childhood antecedents of adult chronic disease. Epidemiol Rev 1996;18:158-74

12 Ben-Shlomo Y, Davey Smith G. Deprivation in infancy and adult life: which is more important for mortality risk? Lancet 1991;337:530-4.

13 Leon DA, Koupilová I, Lithell HO, Berglund L, Mohsen R, Vågerö D, et al. Failure to realise growth potential in utero and adult obesity in relation to blood pressure in 50 year old Swedish men. BMJ 1996;312:401-6.

14 Lithell HO, McKeigue PM, Berglund L, Mohsen R, Lithell U, Leon DA Relation of size at birth to non-insulin dependent diabetes and insulin concentrations in men aged 50-60 years. BMJ 1996;312:406-10.

15 Koupilová I, Leon DA. Size at birth and mortality from ischaemic heart disease and stroke in Swedish men aged 50-70 years. J Epidemiol Community Health 1996;50:592.

16 Koupilová I, Leon DA, McKeigue PM, Lithell HO. Blood pressure as a potential mediator of the association between low birth weight and high cardiovascular mortality. J Hypertension 1997;15(suppl 4):46.

17 Erikson R, Goldthorpe J. The constant flux. A study of class mobility in indus trial countries. Oxford: Oxford University Press, 1992.

18 Stata Corporation. Stata reference manual:release 5. College Station, Texas: Stata Press, 1997.

19 Koupilová I. Fetal growth, social factors and circulatory diseases. Act Uniw Upsaliensis 1997;698:7-60.

20 Frankel S, Elwood P, Sweetnam P, Yarnell J, Davey Smith G. Birthweight, adult risk factors and incident coronary heart disease: the Caerphilly study. Public Health 1996;110:139-43.

21 Kramer MS, Olivier M, McLean FH, Willis DM, Usher RH. Impact of intrauterine growth retardation and body proportionality on fetal and neonatal outcome. Pediatrics 1990;86:707-13.

22 Vik T, Vatten L, Jacobsen G, Bakketeig LS. Prenatal growth in symmetric and asymmetric small-for-gestational-age infants. Early Hum Dev 1997;48:167-76.

23 Kramer MS. Intrauterine growth and gestational duration determinants. Pediatrics 1987;80:502-11.

24 Susser M. Maternal weight gain, infant birth weight, and diet: causa sequences. Am J Clin Nutr 1991;53:1384-96.

(Accepted 16 April 1998)

\title{
Deprivation and emergency admissions for cancers of colorectum, lung, and breast in south east England: ecological study
}

\author{
Allyson M Pollock, Neil Vickers
}

\begin{abstract}
Objectives: To examine the relation between deprivation and acute emergency admissions for cancers of the colon, rectum, lung, and breast in south east England.

Design: Ecological analysis with data from hospital episode statistics and 1991 census.

Setting: North and South Thames Regional Health Authorities (population about 14 million), divided into 10 aggregations of 31470 census enumeration districts (median population 462).

Subjects: 146639 admissions relating to 76552 patients aged $<100$ years on admission, resident in the Thames regions, admitted between 1 April 1992 and 31 March 1995.

Results: Residents living in deprived areas were more likely to be admitted as emergencies and has ordinary inpatient admissions and less likely to be admitted as day cases. Adjusted odds of ordinary admissions from the most deprived tenth occurring as emergencies (relative to admissions from the most affluent tenth) were 2.29 (95\% confidence interval 2.09 to 2.52 ) for colorectal cancer, 2.20 (1.99 to 2.43) for lung cancer, and 2.41 (2.17 to 2.67) for female breast cancer; adjusted odds of admissions as day cases were 0.70 (0.64 to 0.76$), 0.50$ (0.44 to 0.56 ), and 0.56 (0.50 to
\end{abstract}

0.62), respectively. Patients from deprived areas with lung or breast cancers were less likely to be recorded as having surgical interventions. Adjusted odds of patients from the most deprived tenth receiving surgery were 0.88 ( 0.78 to 1.00$), 0.58$ (0.48 to 0.70$)$, and 0.63 (0.56 to 0.71 ), respectively. Admissions for colorectal cancer from the most deprived areas were less likely to be to hospitals admitting 100 or more new patients a year; the opposite held true for breast cancer admissions. No association was found for lung cancer admissions.

Conclusions: Earlier diagnostic and referral procedures in primary care in deprived areas are required if there are to be significant reductions in mortality from these cancers. A national information strategy is required to ensure the continued availability of population based data on NHS patients and to mandate standardised datasets from the private sector. Rationalisation of acute services, hospital mergers, and plans for bed closures must take into account the increased healthcare needs and inequities in access to treatment and care of residents in areas with high levels of deprivation. Health authorities and primary care groups should re-examine their purchasing intentions, service reviews, and monitoring arrangements in the light of these findings.
Department of

Public Health

Sciences,

St George's

Hospital Medical

School, London

SW17 0RE

Allyson M Pollock, senior lecturer in

public health medicine

Neil Vickers,

research assistant

Correspondence to: Dr Pollock, School

of Public Policy,

University College

London, London

WC1E 7HN

BMJ 1998;317:245-52 


\section{Introduction}

Associations between social deprivation and cancer survival have been reported for many cancers. ${ }^{1-4}$ For most cancers, stage at presentation remains the single most important source of variation in outcome, and early diagnosis offers the greatest reduction in mortality. Evidence has been reported of variation by deprivation status in the use of primary care services and in hospital admission patterns. The fourth national study of morbidity statistics from general practice found that patients from deprived areas were more likely to consult a general practitioner with a complaint subsequently diagnosed as cancer. ${ }^{5}$ Patients from deprived areas, however, have also been shown to have lower uptake rates for preventive services in general practice, such as screening for cancers of the breast and cervix. ${ }^{6}{ }^{7}$

A major reorganisation of cancer services is under way in England and Wales in response to the policy framework for commissioning cancer services by the Expert Advisory Group on Cancer (EAGC), commonly known as the Calman-Hine report. ${ }^{8}$ The report was commissioned because of concerns about apparent variations in the outcomes of treatment. Acute hospital sector care is the main focus of change: cancer units "of a size to support clinical teams with sufficient skill and facilities to manage the commoner cancers" will be set up in many district general hospitals; cancer centres, based largely in specialist units, will provide skill in the management of all cancers with specialist diagnostic and therapeutic care. For breast cancer, providers will have to admit 100 or more patients a year to apply for unit status. But primary care will also play a part in the new system. Cancer units and cancer centres are to undertake detailed discussions with general practitioners to clarify patterns of referral and diagnosis on the basis of nationally agreed and rigorously evaluated standards.

This paper considers the relation between social deprivation and hospital admissions for the three most common cancers (colorectal, female breast, and lung) in south east England. It was commissioned by South Thames Research and Development Directorate to assist with the implementation of the Calman-Hine report in the Thames regions. To that end we focus on mode of presentation (emergency or elective), type of admission (ordinary inpatient or day case), the caseload of hospitals making the admission, and, as a crude measure of treatment variation, the proportions of patients to receive surgery.

\section{Methods}

Census data

Data from the 1991 census were extracted from the University of Manchester's computer centre on all enumeration districts in the Thames regions. The data comprised the number of people living in each census enumeration district broken down by age (in bands of 5 years) and sex and the variables required to calculate a Townsend material deprivation score. ${ }^{9}$ The enumeration districts were then divided into tenths, on the basis of their Townsend score, with the first tenth containing those enumeration districts with the lowest $10 \%$ of Townsend scores (that is, the most affluent enumera-

\section{Data on finished consultant episodes retrieved} from the Office for National Statistics

Mode of admission (elective, emergency, other) Type of admission (day case, ordinary)

Age at start of finished consultant episode

Date of admission

Date of discharge

Date of start of episode

District health authority of residence

District health authority of treatment

Diagnosis-first to fifth secondary

Diagnosis-primary

Diagnosis-secondary

Date of birth

Home postcode

Length of finished consultant episode (days)

NHS provider code

NHS purchaser code

NHS or private

Procedure-first to fourth

Sex

tion districts) and the last tenth containing those enumeration districts with the highest $10 \%$ of Townsend scores (that is, the most deprived enumeration districts).

\section{NHS data}

Hospital activity in England and Wales is measured in "finished consultant episodes" and not admissions or patients. These episodes are defined as those "where a patient has completed a period of care under a consultant and is either transferred to another consultant or is discharged. ${ }^{10}$ We requested data from the Office for National Statistics and the Department of Health on all ordinary inpatient finished consultant episodes completed by residents of the Thames regions for the financial years 1992-3 to 1994-5 with a primary diagnosis of any of three cancers of interest (ICD-9 (international classification of diseases, ninth revision) codes 153, 154, 162, 174) for patients aged $<100$ years at diagnosis. The information extracted is shown in the box.

By using probability matching, finished consultant episodes were linked to obtain admissions and patients; this was done by a senior member of the Oxford record linkage study, using full date of birth, seven character postcode, and sex as index variables. Full accounts of the method and its assumptions have been published ${ }^{11}{ }^{12} \mathrm{An}$ admission was defined as all finished consultant episodes relating to one inpatient stay; numbers of patients treated were obtained by linking all admissions relating to the same person.

Patients and admissions were assigned to an enumeration district by using a table linking postcode and enumeration district. Postcodes are not coterminous with enumeration districts. When postcodes lay in more than one enumeration district patients were assigned to the "pseudoenumeration" district for the postcode (this is the enumeration district in which most people at a postcode live; there is only one pseudoenumeration district per postcode). ${ }^{13}{ }^{14}$ They were then assigned to Townsend tenths.

A full list of cancer units and cancer centres for the two regions has not yet been finalised so we could not 


\section{Therapeutic and palliative surgical procedures}

Colorectal cancer (ICD-9 codes 153-154)

- H04 Total excision of colon and rectum

- H05 Total excision of colon

- H06 Extended excision of right hemicolon

- H07 Other excision of right hemicolon

- H08 Excision of transverse colon

- H09 Excision of left hemicolon

- H10 Excision of sigmoid colon

- H11 Other excision of colon

- H33 Excision of rectum

- H41 Other operations on rectum through anus

- H47 Excision of anus

- H48 Excision of lesion of anus

Cancer of the lung, trachea, or bronchus

(ICD-9 code 162)

- E52 Other operations on bronchus

- E54 Excision of lung

- E55 Open extirpation of lesion of lung

- E57 Other open operations on lung

- E59 Other operations on lung

- E61 Open operations on mediastinum

Female breast cancer (ICD-9 code 174)

- B27 Total excision of breast

- B28 Other excision of breast

- B29 Reconstruction of breast

- B36 Other operations on breast

The three character code at the beginning of each line was the OPCS (Office of Population Censuses and Surveys) code for the relevant procedure

examine access to these in detail. We could, however, examine access to hospitals treating 100 or more patients a year (a defining criterion of cancer unit status for breast cancer and a useful arbitrary cut off for the other two cancers).

Hospital episode statistics define variables according to special criteria. Day case admissions are defined as inpatient admissions "given electively during the course of a day for care or treatment which can be completed in a few hours." Regular day or regular night attendances on wards are not counted as day case admissions. Emergency admissions are defined as "admissions made at short notice at the request of accident and emergency services, general practitioners, bed bureaux, or consultant outpatient clinics."

Colon and rectal cancers were treated as a single condition. For each tumour site and each tenth of deprivation, we computed, firstly, the number and proportion of day case admissions; secondly, the number and proportion of emergency admissions (as day cases are by definition elective they were excluded from this calculation); thirdly, the number and proportion of admissions to hospitals treating 100 or more patients for the relevant cancer; and, finally, as a crude measure of treatment differences across deprivation tenths, the number and proportion of patients (not admissions) ever to have received therapeutic or palliative surgery (in any admission). The procedures classified as such are listed in the box.
The relative differences between the most affluent tenth and all others were expressed as a percentage with $95 \%$ confidence intervals; methods described by Gardner and Altman were used. ${ }^{15}$ To adjust for age and sex differences across tenths a multiple logistic regression model was derived; the differences between the most affluent tenth and all subsequent tenths with respect to day case admission, emergency admission, admission to a cancer unit, and surgery were expressed as odds ratios taken from this model.

Within each multiple logistic regression model, tests for trend and heterogeneity across tenths were carried out. Heterogeneity was tested by comparing the deviance difference (between models with Townsend tenth and models without Townsend tenth) with a $\chi^{2}$ on $9 \mathrm{df}$. The null hypothesis was that there would be no significant heterogeneity (the deviance difference would be less than a significant $\chi^{2}$ on 9 $\mathrm{df}-$ that is, 16.92 at the $5 \%$ level). Trend was tested by treating Townsend tenth as a continuous variable ( 0 to 9). We then compared the deviance difference

Table 1 Number (\%) of emergency admissions by deprivation status

\begin{tabular}{|c|c|c|c|}
\hline $\begin{array}{l}\text { Distribution of } \\
\text { affluence (tenths) }\end{array}$ & $\begin{array}{l}\text { No (\%) of emergency } \\
\text { admissions }\end{array}$ & $\begin{array}{l}\% \text { difference from most } \\
\text { affluent 10th }(95 \% \mathrm{CI})\end{array}$ & $\begin{array}{l}\text { Odds of emergency } \\
\text { admission }(95 \% \mathrm{Cl})\end{array}$ \\
\hline \multicolumn{4}{|c|}{ Colerectal cancer (ICD-9 codes 153-154) } \\
\hline 1st (affluent) & $1163 / 3374(34.47)$ & & 1.00 \\
\hline 2nd & $1287 / 3762(34.21)$ & $-0.26(-2.47$ to 1.95$)$ & 0.95 (0.87 to 1.04$)$ \\
\hline 3 rd & $1516 / 3877(39.10)$ & 4.63 (2.41 to 6.85$)$ & 1.27 (1.16 to 1.39$)$ \\
\hline 4th & $1393 / 3636(38.31)$ & 3.84 (1.59 to 6.09$)$ & 1.21 (1.10 to 1.32$)$ \\
\hline 5th & $1473 / 3922(37.56)$ & 3.09 (0.88 to 5.29$)$ & 1.18 (1.08 to 1.29$)$ \\
\hline 6th & $1355 / 3322(40.79)$ & $6.32(4.00$ to 8.64$)$ & 1.19 (1.09 to 1.30$)$ \\
\hline 7 th & $1293 / 3205(40.34)$ & 5.87 (3.54 to 8.21$)$ & 1.25 (1.14 to 1.37$)$ \\
\hline 8 th & 1199/2832 (42.34) & 7.87 (5.44 to 10.29$)$ & 1.43 (1.30 to 1.57$)$ \\
\hline$\overline{9 \text { th }}$ & $1304 / 2700(48.30)$ & $13.83(11.35$ to 16.30$)$ & 1.78 (1.62 to 1.96$)$ \\
\hline 10th (deprived) & $1447 / 2603(55.59)$ & 21.12 (18.63 to 23.61) & 2.29 (2.09 to 2.52$)$ \\
\hline \multicolumn{2}{|c|}{ Deviance difference (trend) } & $83.93^{\star}$ & \\
\hline \multicolumn{2}{|c|}{ Deviance difference (heterogeneity) } & $180.37^{\star}$ & \\
\hline Unknown & $218 / 527(41.37)$ & $6.90(2.40$ to 11.40$)$ & $1.14(0.97$ to 1.35$)$ \\
\hline \multicolumn{4}{|c|}{ Cancer of lung, trachea, or bronchus (ICD-9 code 162) } \\
\hline 1st (affluent) & $1156 / 2215(52.19)$ & & 1.00 \\
\hline 2nd & $1492 / 2645(56.41)$ & $4.22(1.41$ to 7.03$)$ & $1.21(1.09$ to 1.34$)$ \\
\hline 3 rd & $1528 / 2663(57.38)$ & 5.19 (2.39 to 7.99$)$ & 1.16 (1.04 to 1.28$)$ \\
\hline 4th & $1801 / 3093(58.23)$ & 6.04 (3.33 to 8.75$)$ & 1.35 (1.22 to 1.49$)$ \\
\hline 5th & $1828 / 3075(59.45)$ & 7.26 (4.55 to 9.97$)$ & 1.38 (1.24 to 1.52$)$ \\
\hline 6th & $1885 / 3223(58.49)$ & 6.30 (3.61 to 8.98$)$ & 1.36 (1.23 to 1.50$)$ \\
\hline 7 th & $1931 / 3173(60.86)$ & 8.67 (5.98 to 11.35$)$ & 1.52 (1.38 to 1.68$)$ \\
\hline 8 th & $2218 / 3542(62.62)$ & 10.43 (7.81 to 13.05$)$ & 1.61 (1.46 to 1.78$)$ \\
\hline 9th & $2344 / 3556(65.92)$ & 13.73 (11.13 to 16.33$)$ & 1.95 (1.77 to 2.15$)$ \\
\hline 10th (deprived) & $2470 / 3654(67.60)$ & 15.41 (12.83 to 17.98$)$ & 2.20 (1.99 to 2.43$)$ \\
\hline \multicolumn{2}{|c|}{ Deviance difference (trend) } & $196.63^{\star}$ & \\
\hline \multicolumn{2}{|c|}{ Deviance difference (heterogeneity) } & $234.46^{*}$ & \\
\hline Unknown & $309 / 524(58.97)$ & $6.78(2.08$ to 11.48$)$ & 1.56 (1.30 to 1.86$)$ \\
\hline \multicolumn{4}{|c|}{ Female breast cancer (ICD-9 code 174) } \\
\hline 1st (affluent) & $869 / 3935(22.08)$ & & 1.00 \\
\hline 2nd & $953 / 4231(22.52)$ & $0.44(-1.37$ to 2.25$)$ & $1.03(0.83$ to 1.13$)$ \\
\hline 3 rd & $974 / 4158(23.42)$ & $1.34(-0.49$ to 3.17$)$ & 1.07 (0.97 to 1.19$)$ \\
\hline 4th & $954 / 3945(24.18)$ & $2.10(0.24$ to 3.96$)$ & 1.09 (0.98 to 1.21$)$ \\
\hline 5th & $956 / 3979(24.03)$ & $1.94(0.09$ to 3.80$)$ & $1.11(1.00$ to 1.22$)$ \\
\hline 6th & $1014 / 3778(26.84)$ & 4.76 (2.84 to 6.67$)$ & 1.25 (1.13 to 1.38$)$ \\
\hline 7 th & $923 / 3537(26.10)$ & 4.01 (2.07 to 5.95$)$ & 1.26 (1.14 to 1.40$)$ \\
\hline 8th & $911 / 3229(28.21)$ & 6.13 (4.11 to 8.15$)$ & 1.27 (1.15 to 1.41$)$ \\
\hline 9th & $972 / 3109(31.26)$ & 9.18 (7.10 to 11.26$)$ & 1.60 (1.45 to 1.78$)$ \\
\hline 10th (deprived) & $1037 / 2807(36.94)$ & 14.86 (12.65 to 17.07$)$ & 2.41 (2.17 to 2.67$)$ \\
\hline \multicolumn{2}{|c|}{ Deviance difference (trend) } & $69.36^{*}$ & \\
\hline \multicolumn{2}{|c|}{ Deviance difference (heterogeneity) } & $227.91^{\star}$ & \\
\hline Unknown & $189 / 711 / \quad(26.58)$ & 4.50 (1.00 to 7.99$)$ & 1.33 (1.11 to 1.59$)$ \\
\hline
\end{tabular}




\begin{tabular}{|c|c|c|c|}
\hline $\begin{array}{l}\text { Distribution of } \\
\text { affluence (tenths) }\end{array}$ & $\begin{array}{l}\text { No }(\%) \text { of } \\
\text { day cases }\end{array}$ & $\begin{array}{l}\% \text { difference from most } \\
\text { affluent 10th }(95 \% \mathrm{Cl})\end{array}$ & $\begin{array}{l}\text { Odds of day case } \\
\text { admission ( } 95 \% \mathrm{Cl})\end{array}$ \\
\hline \multicolumn{4}{|c|}{ Colorectal cancer (ICD-9 codes 153-154) } \\
\hline 1st (affluent) & $2367 / 5738(41.25)$ & & 1.00 \\
\hline 2nd & $2706 / 6467(41.84)$ & 0.59 (-1.16 to 2.34$)$ & $1.03(0.95$ to 1.11$)$ \\
\hline 3rd & $2074 / 5951(34.85)$ & $-6.40(-8.16$ to -4.64$)$ & $0.79(0.73$ to 0.83$)$ \\
\hline 4th & 2043/5677 (35.99) & $-5.26(-7.05$ to -3.48$)$ & $0.84(0.78$ to 0.91$)$ \\
\hline 5th & 2080/6001 (34.66) & $-6.59(-8.34$ to -4.84$)$ & $0.80(0.74$ to 0.87$)$ \\
\hline 6th & $2315 / 5635(41.08)$ & $-0.17(-1.98$ to 1.64$)$ & $1.01(0.94$ to 1.09$)$ \\
\hline 7 th & $1821 / 5026(36.23)$ & $-5.02(-6.86$ to -3.18$)$ & $0.87(0.80$ to 0.94$)$ \\
\hline 8th & $1411 / 4243(33.25)$ & $-8.00(-9.90$ to -6.09$)$ & $0.77(0.70$ to 0.84$)$ \\
\hline 9th & $1342 / 4040(33.22)$ & $-8.03(-9.97$ to -6.10$)$ & $0.73(0.67$ to 0.80$)$ \\
\hline 10th (deprived) & 1336/3938 (33.93) & $-7.33(-9.28$ to -5.37$)$ & $0.70(0.64$ to 0.76$)$ \\
\hline \multicolumn{2}{|c|}{ Deviance difference (trend) } & $400.54^{*}$ & \\
\hline \multicolumn{2}{|c|}{ Deviance difference (heterogeneity) } & $543.83^{*}$ & \\
\hline Unknown & $500 / 1026(48.73)$ & 7.48 (4.17 to 10.79$)$ & $1.20(1.05$ to 1.38$)$ \\
\hline \multicolumn{4}{|c|}{ Cancer of lung, trachea, or bronchus (ICD-9 code 162) } \\
\hline 1st (affluent) & $725 / 2939(24.67)$ & & 100 \\
\hline 2nd & $698 / 3343(20.88)$ & $-3.79(-5.87$ to -1.71$)$ & $0.82(0.73$ to 0.92$)$ \\
\hline 3rd & $824 / 3486(23.64)$ & $-1.03(-3.13$ to 1.07$)$ & 0.96 (0.86 to 1.08$)$ \\
\hline 4th & $726 / 3817(19.02)$ & $-5.65(-7.64$ to -3.65$)$ & 0.73 (0.65 to 0.82$)$ \\
\hline 5 th & $740 / 3812(19.41)$ & $-5.26(-7.26$ to -3.25$)$ & 0.75 (0.66 to 0.84$)$ \\
\hline 6th & $778 / 4001(19.45)$ & $-5.22(-7.21$ to -3.24$)$ & 0.75 (0.67 to 0.84$)$ \\
\hline 7 th & $675 / 3847(17.55)$ & $-7.12(-9.09$ to -5.15$)$ & 0.66 (0.59 to 0.75$)$ \\
\hline 8th & $805 / 4346(18.52)$ & $-6.15(-8.09$ to -4.21$)$ & 0.70 (0.63 to 0.78$)$ \\
\hline 9th & $631 / 4184(15.08)$ & $-9.59(-11.49$ to -7.69$)$ & 0.55 (0.49 to 0.62$)$ \\
\hline 10th (deprived) & $598 / 4250(14.07)$ & $-10.60(-12.47$ to 8.72$)$ & 0.50 (0.44 to 0.56$)$ \\
\hline \multicolumn{2}{|c|}{ Deviance difference (trend) } & $384.48^{\star}$ & \\
\hline \multicolumn{2}{|c|}{ Deviance difference (heterogeneity) } & $416.37^{\star}$ & \\
\hline Unknown & $119 / 643(18.51)$ & $-6.16(-9.54$ to -2.78$)$ & 0.68 (0.55 to 0.85$)$ \\
\hline \multicolumn{4}{|c|}{$\begin{array}{l}\text { Female breast cancer (ICD-9 code 174) } \\
\end{array}$} \\
\hline 1st (affluent) & $1764 / 5698(30.96)$ & & 1.00 \\
\hline 2nd & $2207 / 6438(34.28)$ & $3.32(1.65$ to 4.99$)$ & 1.13 (1.04 to 1.22$)$ \\
\hline $3 \mathrm{rd}$ & 1911/6067 (31.50) & 0.54 (-1.14 to 2.22$)$ & $1.04(0.96$ to 1.13$)$ \\
\hline 4th & 1860/5804 (32.05) & 1.09 (-0.61 to 2.79$)$ & 1.05 (0.97 to 1.14$)$ \\
\hline 5 th & $1798 / 5775(31.13)$ & 0.18 (-1.52 to 1.87$)$ & 0.99 (0.92 to 1.08$)$ \\
\hline 6th & $1790 / 5567(32.15)$ & $1.20(-0.52$ to 2.91$)$ & 1.06 (0.98 to 1.15$)$ \\
\hline 7 th & $1552 / 5088(30.50)$ & $-0.46(2.20$ to 1.29$)$ & 0.95 (0.87 to 1.04$)$ \\
\hline 8th & $1593 / 4820(33.05)$ & 2.09 (0.30 to 3.88$)$ & 1.13 (1.04 to 1.23$)$ \\
\hline 9th & 1292/4399 (29.37) & $-1.59(-3.39$ to 0.22$)$ & 0.90 (0.82 to 0.98$)$ \\
\hline 10th (deprived) & $741 / 3546(20.90)$ & $-10.06(-11.86$ to -8.26$)$ & 0.56 (0.50 to 0.62$)$ \\
\hline \multicolumn{2}{|c|}{ Deviance difference (trend) } & $321.43^{\star}$ & \\
\hline \multicolumn{2}{|c|}{ Deviance difference (heterogeneity) } & $472.13^{*}$ & \\
\hline $\begin{array}{l}\text { Unknown } \\
\end{array}$ & $316 / 1027(30.77)$ & $-0.19(-3.26$ to 2.88$)$ & 0.91 (0.78 to 1.05$)$ \\
\hline
\end{tabular}

(between models that included this continuous variable and models that excluded it) with a $\chi^{2}$ on $1 \mathrm{df}$. The null hypothesis was that no significant trend would be found (the deviance difference would be less than a $\chi^{2}$ on $1 \mathrm{df}-$ that is, 3.84 at the $5 \%$ level).

\section{Results}

\section{Census data}

Townsend data were retrieved on 29 999/31 470 (95\%) census enumeration districts with a median population of 462. Data on the requisite variables were not available for 1143 "special enumeration districts" (communal establishments with populations of at least 100 people) or for 101 "shipping enumeration districts" (enumeration districts covering people resident on ships at the time of the 1991 census). A further 227 enumeration districts were subject to "data suppression" because there were fewer than 50 residents or 16 households.

\section{NHS data}

We retrieved data on 153582 finished consultant episodes for inpatient admissions completed between 1 April 1992 and 31 March 1995 by patients with a primary diagnosis of any of the designated cancers from the Department of Health and the Office for National Statistics. Of these, 150749 (98\%) had home postcodes that could be matched to Townsend tenths.

After matching, there were 146639 admissions: 53742 for colorectal cancer, 38668 for cancers of the lung, trachea, or bronchus, and 54229 for female breast cancer.

For all three cancers the proportion of emergency admissions recorded for patients from the most affluent areas was consistently lower than the proportion for patients from the most deprived areas (table 1): $35 \% v 56 \%$ for colorectal cancer (difference $21 \% ; 95 \%$ confidence interval $19 \%$ to $24 \%$ ); $52 \%$ v $68 \%$ for lung cancer $(15 \% ; 13 \%$ to $18 \%)$; and $22 \% v 37 \%$ for breast cancer $(15 \% ; 13 \%$ to $17 \%)$. The adjusted odds of ordinary admissions from the most deprived tenth occurring as emergencies (relative to admissions from the most affluent tenth) were 2.29 (2.09 to 2.52) for colorectal cancer, 2.20 (1.99 to 2.43) for lung cancer, and 2.41 (2.17 to 2.67) for female breast cancer. Note that day case admissions were excluded from these calculations because they are, by definition, elective. Significant heterogeneity and trends were found across tenths $(\mathrm{P}<0.001$ in all cases $)$.

For all three cancers a higher proportion of admissions from the most affluent tenth were day cases compared with admissions from the most deprived tenth (table 2): $41 \%$ v 34\% for colorectal cancer (difference $7 \% ; 5 \%$ to $9 \%) ; 25 \%$ v $14 \%$ for lung cancer $(11 \% ; 9 \%$ to $12 \%)$; and $31 \% \cup 21 \%$ for breast cancer $(10 \% ; 8 \%$ to $12 \%)$. The adjusted odds of admissions from the most deprived tenth occurring as day cases (relative to admissions from the most affluent tenth) were 0.70 (0.64 to 0.76 ) for colorectal cancer, 0.50 (0.44 to 0.56$)$ for lung cancer, and 0.56 (0.50 to 0.62) for female breast cancer. Significant heterogeneity and trends were found across tenths $(\mathrm{P}<0.001$ in all cases).

For breast cancer no difference was found in the proportion of admissions to hospitals that admitted 100 or more new patients (table 3). For colorectal cancer admissions of patients from affluent areas were more likely to take place at such hospitals: $92 \%$ v $79 \%$ (difference $13 \% ; 11 \%$ to $14 \%$ ); for lung cancer there was a higher proportion of admissions from deprived areas $(77 \%$ v $80 \%$; difference $3 \% ; 1 \%$ to $5 \%)$. The adjusted odds of admission to such hospitals for admissions from the most deprived tenth (relative to admissions from the most affluent tenth) were 0.38 (0.32 to 0.45$)$ for colorectal cancer, 1.04 (0.90 to 1.21) for lung cancer, and 1.21 (1.04 to 1.40) for female breast cancer. Heterogeneity and trend were significant for colorectal cancer $(\mathrm{P}<0.001)$. For lung cancer admissions trend was significant $(\mathrm{P}<0.05)$ but heterogeneity was not. For breast cancer, trend was significant $(\mathrm{P}<0.05)$ but heterogeneity was not.

For all three cancers the proportion of patients recorded as ever having surgery was higher among patients from affluent areas than among patients from deprived areas (table 4): $56 \%$ v $53 \%$ for colorectal cancer (difference $3 \% ; 0 \%$ to $6 \%$ ); $16 \%$ v $10 \%$ for lung cancer $(6 \% ; 3 \%$ to $8 \%)$; and $65 \%$ v $54 \%$ for breast cancer 
(11\%; $8 \%$ to $14 \%)$. The adjusted odds of patients from the most deprived tenth receiving surgery (relative to patients from the most affluent tenth) were $0.88(0.78$ to 1.00$)$ for colorectal cancer, 0.58 (0.48 to 0.70$)$ for lung cancer, and 0.63 ( 0.56 to 0.71 ) for breast cancer in women. Heterogeneity and trend were not significant for surgery for colorectal cancer but were for the two other cancers.

\section{Discussion}

Our results suggest that social deprivation strongly influences mode of admission, type of admission, and odds of surgical treatment for breast, lung, and colorectal cancer. Patients from deprived areas were more likely to be admitted as emergencies and ordinary inpatient (that is, overnight) admissions and less likely to be admitted as day cases. Patients from deprived areas were also less likely to receive therapeutic or palliative surgery (irrespective of the number of admissions experienced). Patients with colorectal cancer from deprived areas were less likely to be admitted to hospitals that admit 100 or more new cases a year whereas women with breast cancer from deprived areas were more likely to be seen at such a hospital. No deprivation gradient was found for the relation between admissions for lung cancer and hospital caseload.

The gradients reported in this study may be true or artefacts. Artefacts could arise from incomplete or inaccurate data from the hospital episode statistics or from differences by deprivation status in the use of the private sector. We will consider these in turn.

\section{Possible artefacts of gradients}

Studies of the completeness and accuracy of hospital episode statistics show mixed results (D Hewitt, Department of Health, personal communication; J Dixon, personal communication). Although we were unable to estimate the validity of the data with which we were supplied, there is no obvious reason why validity should be correlated with deprivation status of patients.

Direct measures of deprivation (through occupation) were not available for this study. The disadvantage of using proxy measures is that some admissions are bound to be wrongly classified (the ecological fallacy); but such misclassification should lead to underestimation of true gradients. There is evidence that such misclassification is small. A recent study by Slogett and Joshi found that excess mortality associated with residence in areas designated as deprived by census based indicators is wholly explained by the concentration in those areas of people with adverse personal or household socioeconomic factors. ${ }^{16}$

In 1992-3 private health care provided an estimated $20.5 \%$ of all acute sector elective surgery in England (its share was lower in previous years). ${ }^{17}$ There are no good data on diagnostic groups and procedures to estimate non-NHS private sector use by cancer patients. A recent study from Preston indicates that use of the private sector is greatest among residents of affluent areas. ${ }^{18}$ As private sector admissions are almost exclusively elective our results probably underestimate any gradient in elective admissions and day case
Table 3 Number (\%) of admissions to cancer units (hospitals admitting 100 or more patients in any given financial year) by deprivation status

\begin{tabular}{|c|c|c|c|}
\hline $\begin{array}{l}\text { Distribution of } \\
\text { affluence (tenths) }\end{array}$ & $\begin{array}{l}\text { No }(\%) \text { admitted to } \\
\text { cancer unit }\end{array}$ & $\begin{array}{l}\% \text { difference from most } \\
\text { affluent 10th }(95 \% \mathrm{CI})\end{array}$ & $\begin{array}{l}\text { Odds of cancer unit } \\
\text { admission }(95 \% \mathrm{CI})\end{array}$ \\
\hline \multicolumn{4}{|c|}{ Colorectal cancer (ICD-9 codes 153-154) } \\
\hline 1st (affluent) & $5293 / 5738(92.24)$ & & 1.00 \\
\hline 2nd & $5920 / 6467(91.54)$ & $-0.70(-1.67$ to 0.27$)$ & $0.97(0.81$ to 1.16$)$ \\
\hline 3rd & $5406 / 5951(90.84)$ & $-1.40(-2.41$ to -0.39$)$ & 0.90 (0.75 to 1.07$)$ \\
\hline 4th & $5045 / 5678(88.85)$ & $-3.39(-4.46$ to -2.32$)$ & 0.85 (0.71 to 1.02$)$ \\
\hline 5th & $5319 / 6002(88.62)$ & $-3.62(-4.68$ to -2.56$)$ & 1.07 (0.89 to 1.29$)$ \\
\hline 6th & $4919 / 5635(87.29)$ & $-4.95(-6.06$ to -3.84$)$ & 0.85 (0.71 to 1.02$)$ \\
\hline 7 th & $4345 / 5026(86.45)$ & $-5.79(-6.97$ to -4.62$)$ & 0.96 (0.79 to 1.16$)$ \\
\hline 8th & $3579 / 4243(84.35)$ & $-7.89(-9.19$ to -6.60$)$ & $0.74(0.62$ to 0.90$)$ \\
\hline 9th & $3243 / 4040(80.27)$ & $-11.97(-13.38$ to -10.56$)$ & 0.45 (0.38 to 0.53$)$ \\
\hline 10th (deprived) & $3130 / 3939(79.46)$ & $-12.78(-14.22$ to -11.34$)$ & $0.38(0.32$ to 0.45$)$ \\
\hline \multicolumn{2}{|c|}{ Deviance difference (trend) } & $189.33^{*}$ & \\
\hline \multicolumn{2}{|c|}{ Deviance difference (heterogeneity) } & $349.87^{\star}$ & \\
\hline Unknown & $886 / 1026(86.35)$ & $-5.89(-8.10$ to -3.68$)$ & $0.49(0.37$ to 0.64$)$ \\
\hline \multicolumn{4}{|c|}{ Cancer of lung, trachea, or bronchus (ICD-9 code 162) } \\
\hline 1st (affluent) & $2277 / 2940(77.45)$ & & 1.00 \\
\hline 2nd & $2563 / 3343(76.67)$ & $-0.78(-2.86$ to 1.30$)$ & $1.06(0.91$ to 1.23$)$ \\
\hline $3 \mathrm{rd}$ & $2643 / 3486(75.82)$ & $-1.63(-3.71$ to 0.44$)$ & $0.93(0.81$ to 1.08$)$ \\
\hline 4th & $2931 / 3816(76.82)$ & $-0.64(-2.66$ to 1.38$)$ & $0.93(0.80$ to 1.07$)$ \\
\hline 5th & 2894/3812 (75.92) & $-1.53(-3.56$ to 0.50$)$ & 0.84 (0.73 to 0.97$)$ \\
\hline 6th & $3014 / 4001(75.33)$ & $-2.12(-4.13$ to -0.10$)$ & 0.88 (0.76 to 1.01$)$ \\
\hline 7 th & $2909 / 3847(75.62)$ & $-1.83(-3.86$ to 0.20$)$ & 0.90 (0.78 to 1.04$)$ \\
\hline 8 th & $3347 / 4346(77.01)$ & $-0.44(-2.40$ to 1.53$)$ & $1.00(0.86$ to 1.15$)$ \\
\hline 9th & $3194 / 4186(76.32)$ & $-1.13(-3.11$ to 0.86$)$ & $0.96(0.83$ to 1.10$)$ \\
\hline 10th (deprived) & $3411 / 4249(80.28)$ & $2.83(0.90$ to 4.76$)$ & $1.04(0.90$ to 1.21$)$ \\
\hline \multicolumn{2}{|c|}{ Deviance difference (trend) } & 0.13 & \\
\hline \multicolumn{2}{|c|}{ Deviance difference (heterogeneity) } & $22.02^{\star}$ & \\
\hline Unknown & $508 / 643(79.00)$ & $1.56(-1.94$ to 5.05$)$ & 0.75 (0.59 to 0.95$)$ \\
\hline \multicolumn{4}{|c|}{ Female breast cancer (ICD-9 code 174) } \\
\hline 1st (affluent) & $4971 / 5697(87.26)$ & & 1.00 \\
\hline 2nd & $5676 / 6438(88.16)$ & $0.91(-0.26$ to 2.08$)$ & $1.13(1.00$ to 1.28$)$ \\
\hline 3rd & $5264 / 6067(86.76)$ & $-0.49(-1.71$ to 0.72$)$ & 1.00 (0.88 to 1.13$)$ \\
\hline 4th & $5065 / 5804(87.27)$ & $0.01(-1.21$ to 1.23$)$ & $1.11(0.98$ to 1.26$)$ \\
\hline 5th & $5033 / 5774(87.17)$ & $-0.09(-1.31$ to 1.13$)$ & $1.00(0.88$ to 1.13$)$ \\
\hline 6th & $4867 / 5567(87.43)$ & $0.17(-1.06$ to 1.40$)$ & 1.07 (0.94 to 1.22$)$ \\
\hline 7th & $4416 / 5088(86.79)$ & $-0.46(-1.73$ to 0.81$)$ & 1.10 (0.96 to 1.25$)$ \\
\hline 8 th & $4212 / 4820(87.39)$ & $0.13(-1.15$ to 1.41$)$ & 1.18 (1.03 to 1.35$)$ \\
\hline 9th & 3816/4398 (86.77) & $-0.49(-1.81$ to 0.83$)$ & $1.10(0.96$ to 1.27$)$ \\
\hline 10th (deprived) & $3057 / 3546(86.21)$ & $-1.05(-2.47$ to 0.38$)$ & 1.21 (1.04 to 1.40$)$ \\
\hline \multicolumn{2}{|c|}{ Deviance difference (trend) } & $4.28^{\star}$ & \\
\hline \multicolumn{2}{|c|}{ Deviance difference (heterogeneity) } & 16.07 & \\
\hline Unknown & $894 / 1027(87.05)$ & $-0.21(-2.44$ to 2.02$)$ & 0.86 (0.69 to 1.08$)$ \\
\hline
\end{tabular}

admissions (which are closely correlated with elective ordinary admissions).

None of these factors, either on its own or in combination, seems sufficient to account for the gradients reported here.

\section{True sources of gradients}

Deprivation gradients in elective admissions

The most intuitively attractive explanation for the observed deprivation gradients in elective admissions and day case admissions is stage at presentation. ${ }^{19}$ Many studies have reported an association between deprivation and screening services for breast cancer. A recent study in the United States found that low income was a strong predictor of underuse of mammography. ${ }^{20}$ Similar findings have been reported in the United Kingdom for screening for both cervical and breast cancer. In two recent studies Majeed et al found significant negative correlations between rates of 
Table 4 Number (\%) of patients who ever received therapeutic or palliative surgery, by deprivation status

\begin{tabular}{|c|c|c|c|}
\hline $\begin{array}{l}\text { Distribution of } \\
\text { affluence (tenths) }\end{array}$ & $\begin{array}{c}\text { No (\%) who received } \\
\text { surgery }\end{array}$ & $\begin{array}{l}\% \text { difference from most } \\
\text { affluent 10th }(95 \% \mathrm{CI})\end{array}$ & $\begin{array}{l}\text { Odds of ever receiving } \\
\text { surgery }(95 \% \mathrm{Cl})\end{array}$ \\
\hline \multicolumn{4}{|c|}{ Colorectal cancer (ICD-9 codes 153-154) } \\
\hline 1st (affluent) & $1456 / 2606(55.87)$ & & 1.00 \\
\hline 2nd & 1549/2774 (55.84) & $-0.03(-2.69$ to 2.62$)$ & $1.00(0.89$ to 1.11$)$ \\
\hline 3 rd & $1638 / 2859(57.29)$ & $1.42(-1.21$ to 4.05$)$ & $1.05(0.94$ to 1.17$)$ \\
\hline 4th & 1557/2832 (54.98) & $-0.89(-3.54$ to 1.75$)$ & $0.96(0.86$ to 1.07$)$ \\
\hline 5th & $1571 / 2782(56.47)$ & $0.60(-2.05$ to 3.25$)$ & 1.01 (0.91 to 1.13$)$ \\
\hline 6th & $1398 / 2521(55.45)$ & $-0.42(-3.14$ to 2.30$)$ & 0.97 (0.87 to 1.09$)$ \\
\hline 7 th & $1366 / 2445(55.87)$ & $0.00(-2.74$ to 2.74$)$ & $0.99(0.89$ to 1.11$)$ \\
\hline 8th & $1237 / 2153(57.45)$ & $1.58(-1.24$ to 4.41$)$ & $1.06(0.94$ to 1.19$)$ \\
\hline 9th & $1154 / 2047(56.38)$ & $0.50(-2.37$ to 3.38$)$ & $1.01(0.90$ to 1.14$)$ \\
\hline 10th (deprived) & $985 / 1869(52.70)$ & $-3.17(-6.13$ to -0.21$)$ & $0.88(0.78$ to 1.00$)$ \\
\hline \multicolumn{2}{|c|}{ Deviance difference (trend) } & 1.08 & \\
\hline \multicolumn{2}{|c|}{ Deviance difference (heterogeneity) } & 12.31 & \\
\hline Unknown & $245 / 416(58.89)$ & $3.02(-2.07$ to 8.12$)$ & $1.14(0.92$ to 1.40$)$ \\
\hline \multicolumn{4}{|c|}{ Cancer of lung, trachea, or bronchus (ICD-9 code 162) } \\
\hline 1st (affluent) & $256 / 1642(15.59)$ & & 1.00 \\
\hline 2nd & 265/1976 (13.41) & $-2.18(-4.49$ to 0.13$)$ & 0.85 (0.71 to 1.03$)$ \\
\hline $3 \mathrm{rd}$ & $274 / 2107(13.00)$ & $-2.59(-4.85$ to -0.32$)$ & $0.83(0.69$ to 1.00$)$ \\
\hline 4th & $287 / 2276(12.61)$ & $-2.98(-5.20$ to -0.76$)$ & $0.80(0.67$ to 0.96$)$ \\
\hline 5th & $277 / 2382(11.63)$ & $-3.96(-6.14$ to -1.79$)$ & $0.74(0.61$ to 0.89$)$ \\
\hline 6th & $287 / 2446(11.73)$ & $-3.86(-6.03$ to -1.69$)$ & $0.73(0.61$ to 0.88$)$ \\
\hline 7 th & 288/2446 (11.77) & $-3.82(-5.99$ to -1.65$)$ & $0.74(0.62$ to 0.89$)$ \\
\hline 8th & $333 / 2533(13.15)$ & $-2.44(-4.64$ to -0.25$)$ & $0.82(0.68$ to 0.98$)$ \\
\hline 9th & $342 / 2595(13.18)$ & $-2.41(-4.60$ to -0.23$)$ & 0.82 (0.69 to 0.98$)$ \\
\hline 10th (deprived) & $260 / 2581(10.07)$ & $-5.52(-7.62$ to -3.41$)$ & $0.58(0.48$ to 0.70$)$ \\
\hline \multicolumn{2}{|c|}{ Deviance difference (trend) } & $19.04^{\star}$ & \\
\hline \multicolumn{2}{|c|}{ Deviance difference (heterogeneity) } & $39.72^{\star}$ & \\
\hline Unknown & $61 / 434(14.06)$ & $-1.54(-5.25$ to 2.18$)$ & $0.81(0.60$ to 1.11$)$ \\
\hline \multicolumn{4}{|c|}{ Female breast cancer (ICD-9 code 174) } \\
\hline 1st (affluent) & $1927 / 2953(65.26)$ & & 1.00 \\
\hline 2nd & 1980/3053 (64.85) & $-0.40(-2.81$ to 2.01$)$ & 0.99 (0.89 to 1.10$)$ \\
\hline 3 rd & $2054 / 3171(64.77)$ & $-0.48(-2.87$ to 1.91$)$ & $0.99(0.89$ to 1.10$)$ \\
\hline 4th & 1980/3031 (65.32) & $0.07(-2.34$ to 2.48$)$ & $1.02(0.92$ to 1.13$)$ \\
\hline 5th & $1845 / 2936(62.84)$ & $-2.42(-4.87$ to 0.04$)$ & 0.91 (0.82 to 1.01$)$ \\
\hline 6th & $1727 / 2809(61.48)$ & $-3.77(-6.26$ to -1.29$)$ & $0.86(0.77$ to 0.96$)$ \\
\hline 7th & $1661 / 2655(62.56)$ & $-2.69(-5.21$ to -0.18$)$ & 0.90 (0.81 to 1.01$)$ \\
\hline 8th & 1472/2394 (61.49) & $-3.77(-6.37$ to -1.17$)$ & $0.86(0.77$ to 0.97$)$ \\
\hline 9th & $1352 / 2244(60.25)$ & $-5.01(-7.66$ to -2.35$)$ & 0.81 (0.73 to 0.91$)$ \\
\hline 10th (deprived) & $1094 / 2025(54.02)$ & $-11.23(-14.00$ to -8.46$)$ & $0.63(0.56$ to 0.71$)$ \\
\hline \multicolumn{2}{|c|}{ Deviance difference (trend) } & $73.38^{\star}$ & \\
\hline \multicolumn{2}{|c|}{ Deviance difference (heterogeneity) } & $103.67^{\star}$ & \\
\hline Unknown & $345 / 559(61.72)$ & $-3.54(-7.92$ to 0.84$)$ & 0.85 (0.70 to 1.02$)$ \\
\hline
\end{tabular}

breast and cervical cancer screening in a South Thames health commission and variables used in the calculation of the Townsend index, such as overcrowding, not owning a car, and unemployment. ${ }^{67}$ They also found that some general practice factors were associated with higher uptake rates. All of these findings are consistent with deprivation gradients in stage at presentation. For colorectal cancer and lung cancer no comparable programme of mass screening exists, so precise data for primary care are not available.

The cancers under review vary greatly in 5 year survival. Cancers with poor survival have less time for differences in stage at presentation to arise. For this reason we might expect the difference in the proportions of elective admissions between the most affluent and the most deprived tenth to be greatest among admissions for breast cancer (with 65\% relative survival rate at 5 years) and smallest among admissions for lung cancer (with 7\%), with admissions for colo- rectal cancer coming somewhere in between (35\%). But in fact, for all three tumour sites, patients from affluent areas were consistently advantaged with regard to elective admission (and to a roughly similar extent). This strongly suggests that factors unrelated to the tumour are also at work.

It may be that patients from deprived areas do not report symptoms at the primary care stage, contributing to the relatively higher proportions of emergency admissions given to patients from deprived areas. Alternatively, general practitioners may be more alert to symptoms among affluent patients, regardless of risk. Chaturvedi and Ben-Shlomo, in a study of the relation between consultation rates in general practice and surgical provision for six common conditions in the London area, found that people from the most deprived areas were generally least likely to receive surgery despite being most likely to consult a general practitioner with symptoms. ${ }^{21}$ In a study based in New York, Billings et al reported a lack of timely and effective outpatient care for patients from low income areas, leading to higher rates of emergency admissions to hospital. ${ }^{22}$ The only study to consider deprivation gradients in consultation rates for cancer in general practice not confined to screening was the fourth national study (1991-2) of morbidity statistics from general practice; it found that patients of low socioeconomic status were more likely to consult a general practitioner about cancer. ${ }^{5}$ A prospective study is required to examine clinician bias and deprivation gradients in cancer admission rates in the United Kingdom.

The sociodemographic differences in elective inpatient and day case admissions might be explained by increased comorbidity or admissions for reasons other than the tumour. ${ }^{23} 24$ To avoid confounding from admissions other than cancer we included only admissions for which at least one finished consultant episode had a primary diagnosis of one of the three cancers; finished consultant episodes with other primary diagnoses were excluded. For any given admission, the mode of admission recorded for the first finished consultant episode determines the admission status for all subsequent finished consultant episodes, even though the same primary diagnosis may vary.

Admission to hospitals admitting 100 or more new patients a year

The relation between deprivation and admission to a hospital admitting 100 or more new cases a year varied greatly according to the cancer under review (see table 3). Patients with colorectal cancer who resided in deprived areas were far less likely to be seen at such a hospital than their counterparts from affluent areas, whereas patients with lung cancer who resided in deprived areas were more likely to be seen at one. No association between these two variables was found for breast cancer.

This variation might be due in part to the degree to which treatment has been specialised and centralised in specific units. Colorectal cancer services have not been subject to the same degree of specialisation of treatment and organisation as breast cancer services or lung cancer services. Local referral mechanisms are also likely to play a part; it might be that the referral procedures at the disposal of general practitioners 
serving poorer populations result in more patients from those areas being seen at low volume hospitals. It is also possible that general practice referral procedures are influenced by patients' perceived deprivation status. Further work is required to investigate these hypotheses. It is unlikely that in the period under study differences in the proportion of patients in the care of general practitioner fundholders could have significantly affected this gradient.

Deprivation gradients in surgery proportions

The hospital episode statistics dataset does not include data on tumour stage. With these data it is impossible to say whether the differences in the proportion of patients who received surgery reflect real inequalities of treatment or whether they simply reflect stage at presentation. At a population level, various interventions have been shown to increase survival and reduce morbidity for each of the three cancers. But this does not necessarily hold true for the individual patient. For example, overall survival from lung cancer at 5 years has been increased by curative surgical resection (given to early stage cases); but only $10-15 \%$ of lung cancer patients would benefit from it. In the absence of detailed data on the tumour (stage, subsite, size, morphology) it is difficult to identify with certainty cases that have suffered from "inequalities of treatment." Treatment differences might simply reflect differences in patterns of presentation by deprivation status. The much lower proportion of patients with breast cancer from the most deprived tenth ever to receive surgery is worrying indeed; further study is warranted to establish its causes.

The gradients reported here are consistent with the hypothesis that patients from deprived areas present at a later stage in the course of their disease; an analysis of cancer registry data is required to assess whether this is so. Unfortunately, currently available cancer registry data are unequal to this task, partly because staging data are often incomplete but also because of the exceptionally high proportion of cases registered only from death certificates in the Thames registry (up to $25 \%)$. Such cases do not have data on stage and histology.

\section{Conclusion}

The strong deprivation gradients in mode and type of hospital admission for the three cancers under review suggest that, for whatever reason, primary care is failing patients from deprived areas. More effective diagnostic and referral procedures in primary care settings and earlier access to acute hospitals would result in significant reductions in mortality from these diseases. NHS purchasers, including primary care groups, should use the commissioning process to ensure equity in access to cancer care at both primary and secondary level. A national information strategy is required to ensure the continued availability of population based data on NHS patients and to mandate standardised datasets from the private sector. These findings have implications for resource allocation and healthcare planning. Rationalisation of acute services and plans for bed closures must take into account the increased healthcare needs and inequities in access to treatment and care of residents living in areas with high levels of deprivation. Regional
Key messages

- A major reorganisation of cancer services is under way in England and Wales with the aim of improving access to and quality of treatment

- Residents with cancers of the bowel, lung, or breast in deprived areas in the Thames region were more likely to be admitted as emergencies and ordinary inpatients than their counterparts from more affluent areas, and patients with lung or breast cancers from deprived areas were less likely to receive surgical treatment

- Patients with colorectal cancer from the most deprived areas were less likely to be seen at hospitals with a large caseload than were patients from affluent areas; the opposite held true for patients with breast cancer, but no association was found for admissions for lung cancer

- More effective early diagnostic and referral procedures in primary care in deprived areas are required if reductions in mortality are to be achieved

- Hospital mergers and plans for service reconfiguration and bed closures must take into account inequities in access to treatment among residents in deprived areas

outposts, health authorities, and primary care groups should re-examine their purchasing intentions, service reviews, and their monitoring arrangements in the light of these findings. Prospective studies are required to establish the mechanisms by which the deprivation gradients reported here take root.

We thank Mr Leicester Gill of the Oxford record linkage study for carrying out the probability matching on the dataset analysed here, Ms Barbara Butland of St George's Hospital Medical School for statistical advice, Dr Azeem Majeed for advice on using the census, and the anonymous statistical referee for the suggestion that we include a trend and heterogeneity test in the results.

Contributors: AP initiated and designed the study and NV undertook the programming and data analysis. The paper was written jointly.

Funding: South Thames Research and Development Directorate.

Conflict of interest: None.

1 Schrijvers CT, Coebergh JW, van der Heijden LH, Mackenbach JP. Socioeconomic status and breast cancer survival in the southeastern Netherlands, 1980-1989. Eur J Cancer 1995;31A:1660-4.

2 Schrijvers CT, Mackenbach JP, Lutz JM, Quinn MJ, Coleman MP. Deprivation, stage at diagnosis and cancer survival. Int J Cancer 1995;63:324-9.

3 Schrijvers CT, Mackenbach JP, Lutz JM, Quinn MJ, Coleman MP. Deprivation and survival from breast cancer. Br J Cancer 1995;72:738-43.

4 Schrijvers CT, Coebergh JW, van der Heijden LH, Mackenbach JP. Socioeconomic variation in cancer survival in the southeastern Netherlands, 1980-1989. Cancer 1995;75:2946-53.

5 McCormick A, Fleming D, Charlton J. Morbidity statistics from general practice:fourth national study, 1991-92. London: Office of Population Censuses and Surveys, 1994.

6 Majeed FA, Cook DG, Anderson HR, Hilton S, Bunn S, Stones C. Using patient and general practice characteristics to explain variations in cervical smear uptake rates. BMJ 1994;308:1272-6.

7 Majeed FA, Cook DG, Given-Wilson R, Vecchi P, Poloniecki J. Do general practitioners influence the uptake of breast cancer screening? J Med Screening 1995;2:119-24.

8 Expert Advisory Group on Cancer. A policy framework for commissioning cancer services. Leeds: NHS Management Executive, 1994.

9 Townsend P, Phillimore P, Beattie A. Health and deprivation: inequality and the north. London: Croom Helm, 1988. 
10 Government Statistical Service. Hospital episode statistics, 1989-1990. London: HMSO, 1993.

11 Gill L, Goldacre M, Simmons H, Bettley G, Griffith M. Computerised linking of medical records: methodological guidelines. I Epidemiol Community Health 1993;47:316-9.

12 Majeed FA, Voss S. Performance indicators for general practice [editorial]. BMJ 1995;311:209-10.

13 Majeed FA. Deprivation payments to general practitioners [letter]. BMJ 1995;310:1674.

14 Majeed FA, Cook DG, Poloniecki J, Martin D. Using data from the 1991 census. BMJ 1995;310:1511-4.

15 Gardner M, Altman D, eds. Statistics with confidence: confidence intervals and statistical guidelines. London: BMJ Publishing, 1989.

16 Sloggett A, Joshi H. Higher mortality in deprived areas: community or personal disadvantage? BMJ 1994;309:1470-4.

17 Laing's review of private health care, 1995. London: Laing and Buisson, 1996.
18 Lamden KH, Sudell AJ. Access to elective surgery at electoral ward level: the impact of the private sector.J Public Health Med 1995;17:63-4.

19 Blaxter M. Equity and consultation rates in general practice. $B M J$ 1984;288:1963-7.

20 Calle EE, Flanders WD, Thun MJ, Martin LM. Demographic predictors of mammography and Pap smear screening in US women. Am J Public Health 1993:83:53-60.

21 Chaturvedi N, Ben-Shlomo Y. From the surgery to the surgeon: does deprivation influence consultation and operation rates? $\mathrm{Br} J$ Gen Pract 1995;45:127-31.

22 Billings J, Zeitel L, Lukomnik J, Carey TS, Blank AE, Newman L. Impact of socioeconomic status on hospital use in New York City. Health Affairs $1993 ; 12: 162-73$

23 Carstairs V, Morris R. Deprivation and health in Scotland. Health Bull $1990 ; 48: 162-75$

24 Eames M, Ben-Shlomo Y, Marmot MG. Social deprivation and premature mortality: regional comparison across England. BMJ 1993;307:1097-102. (Accepted 16 April 1998)

\title{
Mortality in people taking selegiline: observational study
}

\author{
Margaret Thorogood, Ben Armstrong, Tom Nichols, Jen Hollowell
}

\section{Health Promotion Research Unit, \\ London School of Hygiene and \\ Tropical Medicine \\ London \\ WC1E 7HT \\ Margaret \\ Thorogood, \\ reader in public \\ health and \\ preventative medicine \\ Tom Nichols, \\ research assistant \\ Environmental \\ Epidemiology Unit, \\ London School of \\ Hygiene and \\ Tropical Medicine \\ Ben Armstrong, \\ senior lecturer in \\ medical statistics \\ Office for National \\ Statistics, London \\ SW1V 2QQ \\ Jen Hollowell, \\ General Practice \\ Research Database \\ research manager \\ Correspondence to: Dr Thorogood \\ m.thorogood@lshtm. \\ ac.uk}

BMJ 1998;317:252-4

\begin{abstract}
Objective: To evaluate mortality among patients with Parkinson's disease receiving different treatment.

Design: Cohort study based on computerised medical records.

Setting: UK General Practice Research Database. Subjects: 12621 patients aged between 35 and 90 years who had received a prescription for an antiparkinsonian drug, whether or not a diagnosis of Parkinson's disease had been recorded. Patients prescribed an antipsychotic drug before or at the same time as their first antiparkinsonian drug or before age 35 were excluded to avoid including drug-induced Parkinsonism.

Main outcome measure: Death from any cause. Results: 1720 deaths occurred during 14000 person-years of observation. There was a non-significant $11 \%$ (95\% confidence interval $0 \%$ to $23 \%$ ) increase in the risk of death associated with taking selegiline either alone or in combination with levodopa. The death rate was higher among younger patients (aged under 80 years) and those with a recorded diagnosis of Parkinson's disease taking selegiline alone.
\end{abstract}

Conclusions: The results are compatible with a small excess mortality in people taking selegiline and suggest a larger excess in patients under 80 years of age and those with a confirmed diagnosis of Parkinson's disease taking selegiline without levodopa.

\section{Introduction}

The Parkinson's Disease Research Group trial of drug treatments for Parkinson's disease began in 1985 following earlier indications of a beneficial effect of selegiline. The trial included 822 patients with early Parkinson's disease randomised into one of three treatment arms: levodopa and dopa decarboxylase inhibitor (arm 1), levodopa and dopa decarboxylase inhibitor combined with selegiline (arm 2), and bromocriptine (arm 3). ${ }^{1}$ A pre-planned interim analysis in December 1994 revealed a significant difference in mortality between arms 1 and 2, and the group decided to stop treating patients with selegiline and to publish these results. There was an average of 5.6 years follow up, and the mortality hazard ratio comparing arm 2 with arm 1 was 1.57 (95\% confidence interval 1.07 to 2.31) after adjustment for age, sex, level of disability before treatment, duration of Parkinson's disease, and year of entry to the trial. ${ }^{2}$

After the publication of these results we were asked by the Medicines Control Agency to evaluate mortality among patients taking antiparkinsonian drugs whose medical records were included in the General Practice Research Database.

\section{Methods}

The General Practice Research Database is a longitudinal dynamic database of medical records collected from a panel of general practitioners throughout the United Kingdom. Anonymised patient records are collected regularly from around 500 participating practices providing information on drug treatment, diagnoses, and important clinical events. There are around 3.5 million patients currently registered on the database. The database has been widely used and validated in a range of studies. ${ }^{3}$

Patients registered with a participating practice who were aged between 35 and 90 years and who had received at least one prescription for an antiparkinsonian drug, whether or not a diagnosis of Parkinson's disease had been recorded, were eligible for inclusion. Patients prescribed an antipsychotic drug before or at the same time as their first antiparkinsonian drug and patients prescribed an antiparkinsonian drug before age 35 were excluded to avoid including drug-induced parkinsonism. Age, sex, aspects of medical history, a detailed history of the prescription of antiparkinsonian or antipsychotic drugs, and the fact and date of death were collected. We started follow up on the date a patient's practice began submitting data (earliest in 1987) or when a patient joined the practice, if later, and we ended it six months before the last data collection from the practice (usually in 1996) or when a patient left the prac- 